\title{
La crítica de Emmanuel Lévinas al cristianismo en Difícil libertad, focalizada en los binomios justicia vs. piedad «espiritual» y Torá vs. encarnación
}

Alberto F. Roldán*

\section{Resumen}

En el presente trabajo se analiza la crítica que Emmanuel Lévinas formula al cristianismo en su obra Difícil libertad. Esa crítica se centra especialmente en los binomios opuestos: justicia vs. piedad "espiritual" y Torá vs. encarnación. El autor admite los aspectos positivos que Lévinas destaca en su análisis del papel histórico del cristianismo, pero cuestiona el hecho de que sobredimensione la Torá como el acto más cercano de Dios en detrimento de la encarnación que, según el pensamiento levinasiano, no es posible ni necesaria. En la parte final del trabajo, se encuentra que el posible punto de confluencia entre judaísmo y cristianismo está en la esperanza mesiánica, más allá de las diferentes comprensiones que, sobre ese concepto, sostienen ambas religiones.

\footnotetext{
Doctor en Teología por el Instituto Universitario Isedet de Buenos Aires y Máster en Ciencias Sociales y Humanidades por la Universidad Nacional de Quilmes (mención filosofía social y política). Autor de unos veinte libros dentro del campo de su especialidad, con traducciones al portugués, inglés y alemán. Ha publicado decenas de artículos en revistas científicas. Ha sido profesor visitante y conferencista en universidades de América Latina, Estados Unidos, Europa y Corea del Sur. Director de posgrado del Instituto Teológico FIET y profesor y asesor del Programa Doctoral Latinoamericano de Ciencias Teológicas. Ha participado en jornadas de filosofía moderna organizadas por la cátedra respectiva de la Universidad Nacional de Mar del Plata. Y es profesor de Fenomenología de la Religión en la Universidad del Centro Educativo Latinoamericano de Rosario, Argentina. Dirige la revista: Teología y cultura: www.teologos.com.ar. Contacto: alberto@teologos.com.ar.
} 


\title{
Palabras clave
}

Lévinas, cristianismo, judaísmo, esperanza mesiánica.

\section{Emmanuel Levinas's critique of Christianity in Difficult Freedom focused on justice vs piety "spiritual" and Torah vs incarnation}

\begin{abstract}
In this article analyzes the critics that Emmanuel Levinas poses to Christianity in his work Dificil Libertad. This criticism has the centre especially in the binomials in opposition: Justice vs. "Spiritual" Piety and Tora vs. Incarnation. The author recognizes the positive aspects of the analysis of Levinas about the historical influence of Christianity but he questions the fact of oversizing the Tora as the most nearest act of God in detriment of the incarnation that Levinas considers impossible and unnecessary. In the final section of his work, discovers one possible point of confluence between Judaism and Christianity: the Messianic hope.
\end{abstract}

\section{Keywords}

Lévinas, Christianity, Judaism, Messianic Hope.

El no tan peligrosamente opuesto por los judíos durante tantos siglos a los llamados de la Iglesia no expresa una terquedad absurda, sino en la certeza de que importantes verdades humanas del Antiguo Testamento se pierden en la teología del Nuevo...

La encarnación, para el judío, no es posible ni necesaria. Emmanuel Lévinas 


\section{Introducción}

El presente trabajo consiste en un análisis de la crítica que el filósofo judío Emmanuel Lévinas formula al cristianismo en su obra Difícil libertad. Entendemos que la investigación sobre el modo y los contenidos de esa crítica es importante por varias razones: en primer lugar, la historia del judaísmo ha sido pródiga en críticas y autocríticas a sus propios postulados, ideas y valores; en segundo lugar, nunca debemos olvidarnos que el cristianismo no surge por generación espontánea, sino que es un producto del propio judaísmo: "la salvación proviene de los judíos", dijo Jesús de Nazaret ${ }^{1}$; y, en tercer lugar, es importante tomar en cuenta una crítica que procede de un filósofo que elabora un pensamiento creativo a partir de categorías hebraicas, lo que le ha valido la crítica de ser algo así como "un teólogo encubierto", pero que siempre se ha mostrado respetuoso del pensamiento del Otro, siendo un filósofo que estructura todo su pensamiento en torno a la alteridad y la obligación ética que nos presenta "el rostro del Otro"2. Para este trabajo hemos escogido su libro Difícil libertad, que recoge los ensayos que Lévinas produjo durante los años de posguerra y que, como se mostrará, abundan en los análisis críticos del autor hacia el cristianismo, especialmente católico romano, pero también aplicables al protestantismo.

El trabajo se estructura del siguiente modo: en la primera parte contrastamos la justicia con la piedad cristiana que Lévinas juzga de tendencia espiritual; en la segunda, el contraste se establece entre la Torá y la encarnación, doctrina abiertamente rechazada por Lévinas; en la tercera, exponemos el papel histórico del cristianismo en la visión de Lévinas para, finalmente, reflexionar sobre la posible convergencia de ambas religiones en un punto neurálgico: la esperanza mesiánica.

1 Juan 4.22 Nueva Versión Internacional. NVI. Las citas de la Biblia en el presente trabajo son tomadas de esa versión, a menos que se indique lo contrario.

2 Las obras principales donde Lévinas desarrolla su filosofía de la alteridad son, fundamentalmente: Totalidad e infinito (Salamanca: Sígueme, 1977) y De otro modo que ser, o más allá de la esencia (Salamanca: Sígueme, 1995). 


\section{Justicia vs. piedad «espiritual»}

Reiteradamente Lévinas puntualiza que lo central de la fe del judaísmo es la justicia. Lo hace de varios modos. En el ensayo "Una religión para adultos", el autor señala que la relación ética, central en su filosofía, se da como relación religiosa ya que ambas dimensiones se entrecruzan en la experiencia del creyente. En una crítica a la filosofía que hace del sí mismo la entrada a lo absoluto, "el judaísmo nos enseña una trascendencia real, una relación con Aquel a Quien el alma no puede contener y sin El Cual no puede, de ninguna manera, sostenerse a sí misma" ${ }^{3}$. Para Lévinas, la conciencia de sí "es inseparable de la conciencia de la justicia y de la injusticia. La conciencia de mi injusticia natural, del daño causado a otro en función de mi estructura de Ego, es contemporánea de mi conciencia de hombre. Las dos coinciden" ${ }^{4}$. Esto implica que no existe la posibilidad de tomar conciencia de mí mismo sin, al mismo tiempo, tomar conciencia de mis injusticias y el deber de practicar la justicia. Por otra parte, del mismo modo en que adquiero conciencia de mí mismo a través de la relación con el Otro, también la cercanía con Dios implica justicia tributada al prójimo. Dice Lévinas:

La justicia tributada al otro, a mi prójimo, me brinda una insuperable cercanía a Dios. Cercanía tan íntima como la plegaria y la liturgia, las cuales nada son sin la justicia. Dios no puede recibir nada de las manos del violento. El piadoso es el justo. Justicia es el término que el judaísmo prefiere a otros que evocan más los sentimientos. Porque el amor mismo requiere justicia y mi relación con el prójimo no puede permanecer ajena a la relación que dicho prójimo entabla con un tercero que es, también, mi prójimo ${ }^{5}$.

Desglosando los elementos, tenemos el siguiente planteo:

justicia al prójimo = cercanía a Dios

plegaria $=$ liturgia $=$ justicia

Emmanuel Lévinas, Difícil libertad y otros ensayos sobre judaísmo, 2da. Edición (Buenos Aires: Lilmod, 2008), 61. En adelante DL. Título original: Difficile Liberté, primera edición de 1963, segunda edición de 1976.

Ibíd., 63. Cursivas originales. 


$$
\begin{gathered}
\text { plegaria sin justicia }=\text { rechazo de parte de Dios } \\
\text { Piadoso }=\text { justo } \\
\text { Justicia }>\text { amor }
\end{gathered}
$$

Expliquemos: para el concepto judaico no hay cercanía a Dios que no implique justicia hacia el prójimo, y viceversa. La plegaria, parte de la liturgia del judaísmo, es equivalente a la práctica de la justicia, ya que sin justicia la plegaria es rechazada por Dios puesto que "Dios no puede recibir nada de las manos del violento". Finalmente, mientras el piadoso es el equivalente del justo, la justicia no es equivalente a otra dimensión "espiritual" porque su valor es superior. Aunque no lo consiga aquí, hay un texto clave de Isaías que corrobora el planteo levinasiano:

¿De qué me sirven sus muchos sacrificios? -dice el Señor-.

Harto estoy de holocaustos de carneros

Y de la grasa de animales engordados;

La sangre de toros, corderos y cabras no me complace.

No me sigan trayendo vanas ofrendas,

El incienso es para mí una abominación.

Luna nueva, día de reposo, asambleas convocadas;

ino soporto que con su adoración me ofendan!

¡Lávense, límpiense!

iAparten de mi vista sus obras malvadas!

iDejen de hacer el mal!

iAprendan a hacer el bien!

iBusquen la justicia y reprendan al opresor!

iAboguen por el huérfano y defiendan a la viuda! ${ }^{6}$

El mensaje del profeta es claro: el pueblo de Dios no debe continuar en la práctica que consiste en la sustitución de la justicia por "actitudes piadosas y religiosas": ofrendas, sacrificios, holocaustos. Debe dejar de hacer el mal y, a su vez, practicar el bien. Debe buscar la justicia que, en el contexto histórico, implicaba: reprender al opresor y estar a favor del huérfano y la viuda que, junto al pobre y el extranjero, son los cuatro núcleos humanos privilegiados por el Dios de Israel. Poniendo de relieve la importancia de la justicia y ubicándose en la línea de Isaías que acabamos de exponer, dice Lévinas: 
La relación con lo divino atraviesa la relación con los hombres y coincide con la justicia social: esto es lo que define todo el espíritu de la Biblia judía. Moisés y los profetas no se preocupan por la inmortalidad del alma, sino por el pobre, por la viuda, por el huérfano y por el extranjero ${ }^{7}$.

Lévinas distingue en este planteo concreto la práctica de la justicia social de una "amistad espiritual" carente de compromiso en la relación con el hombre, porque la relación con Dios implica relación con el hombre y "se experimenta y se lleva a cabo en una economía justa". Cita un diálogo entre un romano y un rabí: "¿Por qué tu Dios, que es el Dios de los pobres, no alimenta a los pobres?, pregunta un romano a Rabí Akiba. «Para que podamos escapar a la condena», responde Rabí Akiba"8.

Hay otra dimensión de la justicia: la aspiración de una sociedad justa. Lévinas apela a un diálogo entre tres rabíes:

Rabí Abhú dijo: “El día de la lluvia es más grande que la resurrección de los muertos, ya que la resurrección de los muertos concierne sólo a los justos y la lluvia concierne a los justos y a los injustos." Rabí Jehudá dijo: "El día de la lluvia es tan grande como el día del don de la Torá." Rabí Hama bar Hanina dijo: "El día de la lluvia es más grande como el día en que la tierra y el cielo fueron creados". Subordinación de todas las relaciones posibles entre Dios y los hombres -redención, revelación, creación- a la institución de una sociedad en la cual la justicia, en lugar de permanecer como una aspiración de la piedad individual, tenga la fuerza suficiente para alcanzar a todos sus miembros y, así, poder realizarse $^{9}$.

La resurrección de los muertos, doctrina característicamente hebraica, "círculo cuadrado" para los griegos ${ }^{10}$ y la creación ceden su lugar de preeminencia ante la búsqueda de una sociedad justa. De ahí que el día de la lluvia sea más importante que el día de la resurrección y de la creación, ya que promueve una sociedad que abarque a todos por igual, fruto de una acción de todos y no de una mera piedad individual.

$D L, 65$.

Ibíd.

Ibíd., 66

Recuérdese la abrupta salida de los epicúreos y estoicos cuando san Pablo menciona el tema en Atenas. Cf. Hechos 17. 


\section{Torá vs. encarnación}

Un segundo tema en el que Lévinas pone de manifiesto el contraste entre judaísmo y cristianismo es el de la ley. Tanto la meditación en la Torá como la práctica de los mandamientos pertenecen a la vida cotidiana de los creyentes judíos y de ningún modo es un yugo aunque implica esfuerzo. En el ensayo ya citado, dice Lévinas: "La ley nunca será un yugo para el pueblo judío. Ella comporta su propia alegría, de la que se nutren una vida religiosa y toda la mística judía"11. Por otra parte, en el ensayo titulado "Judaísmo", puntualiza: "la misericordia atenúa los rigores de la Ley sin anularla"12.

Pero tal vez el ensayo que más destaca la importancia de la Ley es el titulado "Amar a la Torá más que a Dios" que data de 1955. El texto plantea una serie de cuestiones dignas de analizar: el ateísmo como estadio previo a la fe en Dios, la crítica a la encarnación y, finalmente, la "concreción" de Dios en la Torá. La primera de las cuestiones, altamente sugestiva, puede desviarnos de nuestro centro de análisis. Con todo, vale la pena mencionarla sucintamente. Dice Lévinas: "En el camino que conduce al Dios único hay una etapa sin Dios. El verdadero monoteísmo debe responder a las legítimas exigencias del ateísmo"13. La osada idea es ampliada sensiblemente en otro ensayo: "Una religión para adultos", donde Lévinas lejos de considerar como blasfemia esa negación de Dios, sostiene que es algo que contribuye a su gloria. Explica:

Constituye una inmensa gloria para el Creador haber creado un ser que lo afirma después de haberlo puesto en duda y de haberlo negado en los prestigios del mito y del entusiasmo; un ser capaz de buscarlo o escucharlo desde lejos, a partir de la separación, a partir del ateísmo. ${ }^{14}$

Para Lévinas, una religión adulta implica la posibilidad de ejercer una forma de ateísmo, la posibilidad de la negación. El monoteísmo 
es una forma de ateísmo porque marca una ruptura con la concepción de lo sagrado, especialmente de los dioses falsos. "Así, para la visión de lo divino que ellos encarnan, el monoteísmo no es sino un ateísmo"15. Un judaísmo adulto conduce a la fe en un Dios adulto, mientras que una fe infantil solo puede relacionarse con un falso dios.

La segunda cuestión que analiza Lévinas en "Amar a la Torá más que a Dios" es el tema de la encarnación. La menciona, críticamente, en dos ocasiones. La primera es cuando, citando la imagen de Kierkegaard, se plantea si acaso es posible que un Dios que oculta su rostro sea reconocido como íntimo, acaso mediante el "salto" paradójico elaborado por el pensador danés. Rechazando tal posibilidad, dice:

Por el contrario, pensamos que aquí se manifiesta la fisonomía particular del judaísmo: la relación entre Dios y el hombre no es una comunión sentimental en el amor de un Dios encarnado, sino una relación entre espíritus por medio de una enseñanza, la enseñanza de la Torá. Es precisamente la palabra no encarnada de Dios la que garantiza un Dios viviente entre nosotros ${ }^{16}$.

Luego, Lévinas cita la frase clave que recoge de Yosel ben Yosel: "Yo Lo amo, pero amo todavía más Su Torá [...] Y aun si Él me decepcionara y me desengañara, no dejaría por ello de observar los preceptos de la Torá"17. La primera parte de la sentencia parece un eco de un texto de Job: "aunque me matare, en él esperaré"18, la segunda pone el acento en los preceptos de la Torá a los cuales el rabí ama todavía más que al Señor. Lévinas se plantea la posibilidad de que esta declaración sea blasfema, pero rechaza tal idea porque entiende que se trata, por lo menos, de una protección al intento de contacto directo con lo Sagrado, sin mediación de razones. Y entonces introduce la segunda crítica a la encarnación, explicando: "lo espiritual no se ofrece como una sustancia sensible sino por medio de la ausencia; Dios es concreto por la Ley y no por la encarnación;

18 Job 13.15 Reina Valera 1960. 
y Su grandeza no es el hálito de Su misterio sagrado"19. ¿Cómo es posible justificar la supremacía del amor a la Torá por sobre el amor a Dios? Lévinas explica finalmente que: "Amar la Torá aun más que a Dios es, precisamente, acceder a un Dios personal contra el cual uno puede rebelarse, es decir, por el cual uno puede morir"20. Es preciso elaborar unas consideraciones críticas a este planteo.

En primer lugar, lo positivo de la reflexión levinasiana es su referencia al ateísmo como estadio previo a la fe en Dios. Es preciso negar a los dioses que, como ídolos, ocupan el lugar del Eterno. Este aspecto es pocas veces analizado en las teologías cristianas y resulta oportuno tomarlo en consideración cuando se habla de fe y ateísmo ya que, de alguna manera, una posibilidad remite a la otra. Es necesario negar para afirmar después y tener, entonces, una fe de adultos. Lo contrario es una fe infantil que no resiste el análisis ni la crítica.

En segundo lugar, no parece que el rechazo de Lévinas a la encarnación -doctrina característicamente cristiana- esté debidamente fundamentado. Lévinas argumenta que la relación del hombre con Dios no es una relación sentimental. Pero, aunque esa relación no sea únicamente sentimental creemos que el Antiguo Testamento incluye los sentimientos y emociones de los patriarcas, profetas y salmistas. Los textos bíblicos reflejan las dimensiones sentimentales y emocionales que Lévinas parece despreciar ${ }^{21}$. A esa relación sentimental Lévinas propone una "relación entre espíritus" que se concreta en la enseñanza de la Torá. Sin embargo, la naturaleza espiritual de esa relación lejos de ser expresión de lo concreto subraya, más bien, lo indescifrable, invisible e inasible de la relación. Y, además, centralizar todo en la enseñanza y dejar de lado lo sentimental, reduciría la

21 El libro de los Salmos pone en evidencia que las emociones y sentimientos están presentes en las relaciones del hombre y la mujer que temen a Dios. Por otra parte, aunque el término lêb, traducido habitualmente "corazón" se refiera a la mente implicando al "hombre que razona", como ha señalado Wolff, también implica "determinadas disposiciones de ánimo como alegría y preocupación". Hans Walter Wolff, op. cit., 69. 
relación Dios-ser humano a una dimensión puramente intelectual y cognitiva, dejando de lado otros aspectos de esa relación que incluye el salto de la fe kierkegaardiano que Lévinas también cuestiona.

Finalmente, afirma que Dios es concreto por la ley y no por la encarnación y que, por ello, es posible amar a un Dios personal. Todavía es más rotundo en otro tramo de su exposición, cuando dice: "La encarnación, para el judío, no es ni posible ni necesaria"22. A ello debemos decir que, más allá de la importancia que tiene la Torá, nada supera la dimensión personal del encuentro con un Dios que se ha encarnado, que ha entrado en tiempo y espacio, que se ha secularizado. En palabras de Hans Küng: "así, en la profundidad de la carne, y no en la altura de una falsa divinidad, se ha revelado

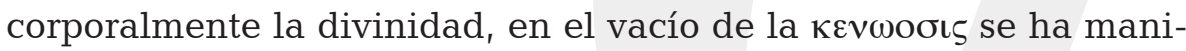
festado el $\pi \lambda \eta \rho \omega \mu \alpha$ de la divinidad (cf. Filp 2,5-11; Col 2,9)"23.

Una consideración especial merece la referencia que Lévinas hace de la ley en cuanto "yugo" para el judaísmo. Dice que nunca

$L D, 225$. Las críticas que Lévinas formula al concepto de "encarnación" en el texto que estudiamos, deben matizarse con otros textos en los que parece acercarse a la idea de encarnación. David Roldán ha analizado el tema a partir del texto de Lévinas "Un Dios hombre", que se incluye en su obra Entre nosotros. Según expone el filósofo y teólogo argentino, Lévinas lucha para superar el problema entre Dios y el mundo cuando se plantea cómo es posible la comunicación entre los dos órdenes. "La idea de encarnación aporta aquí una fuente de inspiración para franquear la barrera: un Dios

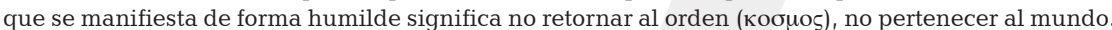
Jesucristo (Lévinas no lo menciona explícitamente, pero de él estamos hablando cuando hablamos de Un Dios hombre) es el apátrida por excelencia: no tiene donde recostar la cabeza (está a merced del prójimo, del sí o no que lo acoge o lo rechaza)." David A. Roldán, "Emmanuel Lévinas y la Ontoteo-logía: Dios, el prójimo y yo", Cuadernos de Teología, vol. xxi (2002): 239. En ese mismo artículo el autor ofrece bibliografía importante sobre el pensamiento de Lévinas recogido por la filosofía y teología latinoamericanas tales como: Pablo Sudar, El rostro del pobre. Inversión del ser y revelación más allá del ser en la filosofía de Lévinas. Su resonancia en la filosofía y teología de la liberación en Latinoamérica (Buenos Aires: UCA, Editora Patria Grande, 1981) y Enrique D. Dussel y Daniel E. Guillot, Liberación latinoamericana y Emmanuel Lévinas (Buenos Aires: Bonum, 1975). También es digna de ser citada la obra más reciente de Alberto Suscasas, Lévinas: Lectura de un palimpsesto (Buenos Aires: Ediciones Lilmod, 2006).

23 Hans Küng, La encarnación de Dios. Introducción al pensamiento de Hegel como prolegómenos para

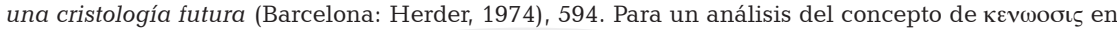
la filosofía de Gianni Vattimo véase Alberto F. Roldán, "La kénosis de Dios en la interpretación de Gianni Vattimo- Hermenéutica después de la cristiandad", Cuadernos de Teología, volumen XxiII (2004): 329-342. 
fue un yugo para el pueblo. ${ }^{24}$ Esta declaración requiere alguna matización. La reinterpretación que el primitivo cristianismo hizo de la ley muestra lo contrario. Tanto la iglesia naciente como la reflexión que San Pablo hace de la ley ponen en evidencia que el judaísmo experimentó, en carne propia, el peso de una ley que no podía cumplir. En el llamado "concilio de Jerusalén" donde se discute la cuestión de la circuncisión como requisito para los gentiles, los apóstoles y ancianos reunidos subrayan la fe como el paso decisivo para la salvación y, en tono crítico, dicen: “Entonces, ¿̇por qué tratan ahora de provocar a Dios poniendo sobre el cuello de esos discípulos un yugo que ni nosotros ni nuestros antepasados hemos podido soportar?"25.

En todo el replanteo que San Pablo hace de la ley de Dios en la vida humana -sobre todo en las cartas a los Gálatas y a los Romanos- queda claro, más allá de lo intrincado de la argumentación, que el camino de la obediencia a la ley divina es una posibilidad pero que, en la realidad histórica, es inviable porque: "La ley no se basa en la fe; por el contrario, «quien practica estas cosas vivirá por ellas»" 26 . La ley exige una total obediencia ya que no se satisface con una obediencia parcial. Luego, cuando el ser humano se encuentra con que no puede cumplir con todo lo demandado por la ley cae en "maldición": "Maldito sea quien no practique fielmente todo lo que está escrito en el libro de la ley"27. En consecuencia, Pablo entiende que el único camino verdadero por el cual el ser humano puede ser justificado por Dios es la fe. Apelando al texto de Habacuq: "el justo

24 En otro texto, Lévinas vuelve a criticar la expresión "yugo de la Ley" sosteniendo: "La obediencia a las prescripciones a través de los actos materiales que esas prescripciones presuponen, es vivida como fervor". "Exigente judaísmo" en Más allá del versículo. Lecturas y discursos talmúdicos (Buenos Aires: Ediciones Lilmod, 2006), 29.

25 Hechos 15.10

26 Gálatas 4.12. En su creativa interpretación de la carta a los Romanos como un texto primario de "teología política", Taubes destaca el papel de San Pablo a quien define como "antiliberal" y quien invierte los valores "poniendo patas para arriba la teología judeo-romano-helenística de las altas esferas, o sea, toda esa mezcolanza que es el helenismo. Cierto que Pablo sigue siendo universal, pero lo es por el ojo de la aguja del Crucificado, lo que quiere decir: la inversión de todos los valores de este mundo. Luego en absoluto el nomos como summum bonum." Jacob Taubes, La teología política de Pablo (Madrid: Trotta, 2007), 39. Cursivas originales. 
vivirá por la fe"28 Pablo concluye que, mediante la fe en el Mesías, el ser humano alcanza la justicia que Dios demanda. Pero entonces surge la pregunta: ¿̇esto significa la anulación definitiva de la ley? Antes de responder esta cuestión es importante plantear, primero, qué entiende Pablo por la "ley de Dios".

Heinrich Schlier dedica un importante excursus a su exposición de Gálatas. A ella recurrimos. Lo primero es que "la problemática de la ley para Pablo se plantea en el horizonte de un concepto de vouos que sobrepasa el sentido de ley y exigencia legal en el judaísmo y, en parte igualmente, el sentido judeocristiano"29. Pablo usa indistintamente el término "ley" para referirse tanto al decálogo como al Pentateuco y, más ampliamente, como el Antiguo Testamento en su conjunto. Pero más allá de esta diversidad de significados, "el concepto vouos tiene el sentido de orden divina"30. Ahora bien: la gran novedad que introduce Pablo en su argumentación es que las exigencias de la Ley de Dios se han cumplido en el Mesías. Volviendo al texto de Gálatas Pablo declara: "Cristo nos rescató de la maldición de la ley al hacerse maldición por nosotros, pues está escrito: «maldito todo el que es colgado de un madero»"31.

Tomando en consideración estos textos, estamos en mejores condiciones para responder la pregunta formulada: "iesto significa la anulación definitiva de la ley?". De alguna manera Pablo formula la misma cuestión luego de exponer el tema de la justicia por la fe en Romanos 3. Dice: "El [Dios] justificará por la fe a los que están circuncidados y, mediante esa misma fe, a los que no lo están. ¿̇uiere decir que anulamos la ley con la fe? iDe ninguna manera! Más bien, confirmamos la ley"32. En su famoso comentario, Karl Barth explica la afirmación paulina relacionando la ley con la fe. Dice: "proclamamos la verdad eterna de la ley al presentar lo paradójico de la fe 
como el No eterno de la ley"33. La fe no invalida a la ley sino que la confirma de varias maneras: en primer lugar, porque en la cruz se cumplieron las exigencias de la ley y, segundo, esas exigencias se cumplen en la "vida en el Espíritu". Dice el apóstol:

Porque lo que era imposible para la ley, por cuanto era débil por la carne, Dios, enviando a su Hijo en semejanza de carne de pecado y a causa del pecado, condenó al pecado en la carne; para que la justicia de la ley se cumpliese en nosotros, que no andamos conforme a la carne, sino conforme al Espíritu ${ }^{34}$.

No es que la justicia de la ley quede obturada por la fe. Esa justicia se cumple ahora, pero en otra dinámica superadora de la anterior: la presencia del Espíritu hace posible el cumplimiento de

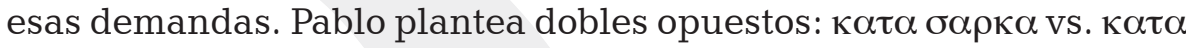

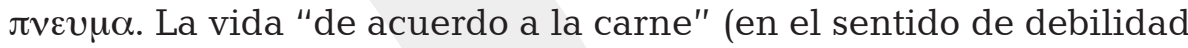
y fragilidad humanas) no puede cumplir con las exigencias de la ley. La vida "de acuerdo al Espíritu" logra ese objetivo. En síntesis:

La lucha del apóstol contra la ley y sus obras, así como la insistencia constante de la necesidad de la fe, sirve para penetrar en la justicia de Dios y, en último término, para la restitución de la Torá original, la ordenación de Dios que bondadosamente exige en orden a la vida ${ }^{35}$.

\section{El papel histórico del cristianismo}

¿Hay alguna posibilidad de confluencia entre el judaísmo y el cristianismo? ¿Hay algún punto en que los caminos de ambas religiones pueden entrecruzarse para el bien de la humanidad? ¿̇ofrece Lévinas algunas pistas para ello? Creemos que sí. Antes de presentarlas es necesario ahondar en lo que el autor dice sobre el papel histórico del cristianismo.

33 Karl Barth, Carta a los Romanos (Madrid: BAC, 1998), 166.

34 Romanos 8.3, 4 Reina Valera 1960.

35 Heinrich Schlier, op. cit., 218. Para un análisis de los conceptos de "carne" y "carnalidad" en el Nuevo Testamento, véase Alberto F. Roldán, “El carácter ambivalente de los conceptos carne y carnalidad en la teología cristiana", Enfoques, año XXII, N. ${ }^{\circ} 1$ (2010): 53-69. 
En "El pensamiento judío hoy" Lévinas reconoce un hecho innegable: el cristianismo ha salido del judaísmo, pero se ha apartado de las presuposiciones éticas del Antiguo Testamento por las cuales la ética es una óptica de lo divino y esta dimensión se manifiesta en el prójimo. Pero no ha sido una relación cordial y fecunda, sino que más bien ha sido "una historia dolorosa, hecha de injusticias y malentendidos, de violencias y rencores" ${ }^{\prime 36}$. Lévinas también admite el papel misionero del cristianismo. Cita a Maimónides, cuya tesis acerca de ese rol implicaba que debía estar al servicio del monoteísmo en el mundo. También menciona a Franz Rosenzweig ${ }^{37}$, pensador decisivo para el propio Lévinas, quien colocaba al judaísmo y el cristianismo en el plano común de una verdad religiosa que no era pluralista, sino más bien dualista. "La verdad -en sí- exigiría una doble significación en el mundo: la del pueblo eterno y la de la misión sobre el camino eterno"38. Pero aunque judaísmo y cristianismo podrían confluir en algún espacio, Lévinas sostiene que la historia muestra dos aspectos: la conquista del cristianismo y el rechazo consecuente por parte del judaísmo. Explica:

Si el cristianismo impresiona por su conquista del mundo occidental, el judaísmo sorprende por su rechazo a reconocer esa conquista. La nuca tensa de ese pueblo, ¿̇no es acaso el rincón sobrenatural de su anatomía? Terquedad más fuerte que las persecuciones, más fuerte que las tentaciones, no eres orgullo -digan lo que digan-, eres libertad ${ }^{39}$.

Lévinas interpreta que ese rechazo del cristianismo en su conquista occidental no es signo de orgullo sino de libertad. Una libertad que, como el título de la obra lo indica, es difícil, adjetivación que

\footnotetext{
$36 \quad D L, 225$

37 En $D L$ se incluye un capítulo titulado "Entre dos mundos (El camino de Franz Rosenzweig)" donde Lévinas analiza el pensamiento del filósofo judío cuya obra clave es La estrella de la redención. Un aspecto que tiene que ver con nuestro tema es que más allá de que Rosenzweig rechazó finalmente la conversión al cristianismo, destaca su lugar en la historia y, contrastándolo con el judaísmo, sostiene que mientras el judaísmo es vivido como si fuera ya la vida eterna, la eternidad del cristiano "es vivida como una marcha, como un camino. La Iglesia cristiana es esencialmente misión. De la Encarnación a la Parusía, el cristianismo atraviesa el mundo para transformar la sociedad paga en sociedad cristiana." $D L, 266$.

38 Ibíd., 229-230.

39 Ibíd., 153.
} 
es explicada en otro ensayo: "Educación y plegaria". Allí, al final de la reflexión, Lévinas critica a los "creadores de un mundo mejor" que encierran y amurallan a nuestros hijos, al modo de los ladrillos vivientes del Egipto bíblico. Inserta entonces la clave hermenéutica de su título: "Y en esos bloques uniformes que deberían prefigurar una humanidad de iguales, se manifiesta -iextraña germinación en una materia tan homogénea!- la Diferencia bajo la cual se agita, obstinada y difícil, la libertad"40.

En "Por un humanismo hebraico", Lévinas vuelve a explicar la llamada "terquedad" de parte del judaísmo hacia los llamados del cristianismo. Dice:

El no tan peligrosamente opuesto por los judíos durante tantos siglos a los llamados de la Iglesia no expresa una terquedad absurda, sino en la certeza de que importantes verdades humanas del Antiguo Testamento se pierden en la teología del Nuevo. ${ }^{41}$

De modo que el rechazo que hace el judaísmo al cristianismo radica en una "aparente" terquedad que no es tal, sino que se explica de dos modos: uno, su opción por una "difícil libertad" y, segundo, por el reduccionismo que la teología del Nuevo Testamento hace de importantes verdades humanas presentes en el Antiguo. Admitir esta objeción o refutarla en forma cabal requeriría dedicar un amplio desarrollo que aquí no estamos en condiciones de encarar. Sólo nos permitimos dos observaciones. La primera, que ciertamente el Nuevo Testamento implica cierto "clima" diferente al Antiguo Testamento. El hecho es reconocido por José Míguez Bonino al admitir que hay un cambio cuando entramos al Nuevo Testamento, particularmente en la literatura joánica y paulina, pero el problema consiste en determinar cuál es ese cambio. Para Míguez Bonino las explicaciones que se han dado son hijas del intelectualismo helénico y de viejas herejías gnósticas y marcionista. Explica:

40 Ibíd., 365. Cursivas originales.

41 Ibíd., 369. 
[...] son las que pretenden que el Nuevo Testamento es "más espiritual" o "más religioso" que el Antiguo. Este tendría que ver con la historia, aquél con la eternidad. Bien sabemos hoy que esa distinción es ajena al pensamiento bíblico. La facilidad con la que el liberalismo y el modernismo -con su inspiración idealista- han aceptado estas explicaciones, ya debería hacernos sospechar de ellas ${ }^{42}$.

Tampoco se puede desconocer el hecho de la inculturación del mensaje cristiano en el mundo helénico. Era un paso necesario, aunque implicaba ciertos riesgos. Juan Luis Segundo, reflexionando sobre el tema, admite que no todo fue positivo en ese diálogo ya que esa inculturación tuvo sus aspectos negativos. "En efecto, hay que admitir que todo estaba lejos de ser perfecto, o siquiera positivo, en ese mundo helénico con el que la Iglesia dialoga en la época patrística"43. Entre las cosas negativas que tal inculturación implicó, está la tendencia "celestial" que fue adquiriendo el cristianismo y que se expresó en cuestiones como "la inmortalidad del alma" y el dualismo antropológico. Sobre el primer tema, remitimos al clásico trabajo de Oscar Cullmann: "¿̇nmortalidad del alma o resurrección de los muertos?"44 donde el teólogo reformado muestra claramente que la noción de inmortalidad del alma es característicamente griega y suplanta al concepto hebraico de "resurrección de los muertos". En cuanto al dualismo antropológico, en su meduloso estudio Antropología del Antiguo Testamento, Hans Wolff muestra dónde surgieron los problemas de traducción de los términos hebreos al griego:

Al traducirse los sustantivos más frecuentes casi siempre por: "corazón", "alma", "carne" y "espíritu", se ha dado lugar a grandes malentendidos. Estos arrancaron ya de los LXX y llevaron equivocadamente a una antropología dicotómica o tricotómica, en la que el cuerpo, el alma y el espíritu se oponen mutuamente. Hay que examinar cómo una filosofía América Latina (El Paso: CBP, 1975), 78. Para un análisis del concepto "Reino de Dios" en relación a la missio Dei y sus mediaciones políticas. Cf. Alberto F. Roldán, Reino, política y misión (Lima: Ediciones Puma, 2011).

43 Juan Luis Segundo, El dogma que libera (Santander: Sal Terrae, 1989), 231.

44 En Oscar Cullmann, Del evangelio a la formación de la teología cristiana (Salamanca: Sígueme, 1972), 233-267 
griega, mediante la misma lengua, ha llegado a suplantar ideas semíticobíblicas ${ }^{45}$.

En cuanto a la creciente tendencia por transferir las realidades terrenas a una esfera celestial, Croatto la atribuye al proceso de helenización del cristianismo que

[...] nos hizo jugar con el "otro mundo", entendido como el reino de lo inmortal y descarnado, y la salvación de todos los males de este mundo. Las cosas se solucionarán después. Pero en un universo que nada tiene que ver con el presente. En ello se da la conjunción del inmortalismo platónico-plotiniano con el apocalipticismo bíblico. Esa línea dominó en el cristianismo tradicional, sobre todo desde el neoplatónico San Agustín ${ }^{46}$.

A la luz de estas reflexiones, se puede percibir que la crítica de Lévinas a la pérdida de muchas verdades del Antiguo Testamento, por parte de la teología del Nuevo, tiene cierto fundamento. De todos modos hay que aclarar que esa pérdida fue gradual, que no sería totalmente atribuible a los escritores del Nuevo Testamento, sino a la posterior helenización del cristianismo, por caso en Alejandría, y que una mirada más amplia al problema implica el desafío, por parte del cristianismo, de tomar en serio el Antiguo Testamento como base de su fe, evitando las tendencias "neotestamentarias" que se reflejan en algunas iglesias cristianas que, en el fondo, son marcionistas.

Más allá de la conquista de Occidente por parte del cristianismo, este ha fracasado en el plano político y social. Lévinas reconoce la pureza de los actos individuales de los cristianos que salvaron vidas de sobrevivientes durante los años terribles de persecución y muerte. "Pero el fracaso del cristianismo en el plano político y social no puede negarse" 47 . Pese a ello, "el cristianismo es una fuerza determinante de la existencia occidental" 48 .

Hans Walter Wolff, op. cit., 21. Para un análisis crítico de la antropología griega inserta en el cristianismo véase Enrique D. Dussel, Antropología de la cristiandad (Buenos Aires: Guadalupe, 1974).

46 José Severino Croatto, "La dimensión política del Cristo libertador" en José Míguez Bonino et. ál., Jesús: ni vencido ni monarca celestial (Buenos Aires: Tierra Nueva, 1977), 170. Cursivas originales.

$47 \quad D L, 153$

48 Ibíd., 255. 
Hemos visto que en el análisis que Lévinas hace del cristianismo hay aspectos positivos y negativos. Le reconoce su misión universalista que ha desarrollado en Occidente y los valores y prácticas de cristianos que individualmente han mostrado solidaridad con el prójimo. Ha señalado que el cristianismo surgió del judaísmo pero que redujo muchas verdades del Antiguo Testamento, importantes para la vida humana terrena y concreta, transfiriéndolas a un plano "celestial". Los llamados que el cristianismo ha hecho a través de los siglos al judaísmo no fueron oídos por este, no por testarudez sino por una libertad obstinada y difícil. Planteadas así las relaciones entre judaísmo y cristianismo i̇es posible alguna confluencia entre ambas expresiones milenarias de la fe de Abraham? A eso vamos en el último segmento de nuestro análisis.

\section{La posible confluencia}

Significativamente, el punto neurálgico a partir del cual se podría pensar en una convergencia entre judaísmo y cristianismo es el Mesías o, mejor expresado: la esperanza mesiánica. Lévinas dice: "La espera mesiánica de los judíos conserva todo su sentido para un cristiano que espera el retorno del Salvador, que espera la Parusía. No todo está consumado, inclusive para un cristiano"49. En el capítulo "Textos mesiánicos" -que por su riqueza merecería un análisis pormenorizado que no encaramos aquí- Lévinas aclara de qué concepción de Mesías está hablando. "Poco y nada podemos decir del Mesías si pretendemos representarlo como una persona que, milagrosamente, viene a poner fin a la violencia que domina al mundo, a la injusticia y a las contradicciones que desgarran a la humanidad"50. La espera del Mesías, según Lévinas, comporta cierto elemento irracional, en el sentido de "algo que no depende del hombre, que viene de afuera: la resolución de las contradicciones políticas"51. 
Con respecto a cuándo llegará el Mesías, Lévinas recoge un diálogo entre Rabí Yehoshúa ben Levy con el profeta Elías. Cierto día el Rabí tuvo la suerte de encontrarse con ese profeta que, en la tradición bíblica, es precursor del Mesías. Rabí Yohoshúa le plantea una única pregunta: "¿Cuándo vendrá el Mesías?" Elías le responde:

"Ve a interrogar al propio Mesías". “¿Dónde encontrarlo?" Permanece a las puertas de Roma. Está allí entre los justos que sufren, entre los mendigos cubiertos de llagas. Rabí Yehoshúa ben Levy se dirige hacia allí. Encuentra una verdadera corte de los milagros. Los cuerpos de aquellos desdichados están cubiertos de vendas. Se las quitan para curarse y se las vuelven a poner. Entre ellos se puede reconocer fácilmente al Mesías ${ }^{52}$.

Lévinas admite esta presencia de un Mesías que sufre. Pero rechaza la idea de que la salvación dependa de ese sufrimiento. Porque "el sufrimiento del Mesías y, por ende, el sufrimiento de la humanidad que sufre en el Mesías y el sufrimiento de la humanidad por la cual sufre el Mesías no bastan para salvar a la humanidad"53. Es claro que de este punto -crucial para el cristianismo- Lévinas toma distancia sustancial: el Mesías sufre y la humanidad sufre en él, pero ningún sufrimiento es suficiente para la salvación. Para Lévinas, la noción judaica del Mesías supera la concepción del cristianismo, que juzga de "mítica". Porque, a partir de que el Mesías es el justo que sufre (Lévinas cita el famoso pasaje de Isaías 53), entonces: “El hecho de no eludir la carga impuesta por el sufrimiento de los otros define la ipseidad misma. Todas las personas son el Mesías" ${ }^{\prime 54}$. En otras palabras: "esto significa, concretamente, que cada uno debe actuar como si fuera el Mesías"55.

Estas reflexiones de Lévinas sobre el Mesías diluyen la idea de un Mesías personal que irrumpe al fin de la historia. El Mesías puede ser cualquiera que sustituya al Otro en el sufrimiento. Pero, de todos

\footnotetext{
52 Ibíd., 124.

53 Ibíd., 125. Resulta interesante constatar que también Taubes, al interpretar el mesianismo que elabora San Pablo dice que, "como el siervo de Dios de Isaías se identifica con el Israel que padece, del mismo modo Pablo identifica al Mesías que padece con la humanidad que padece." Jacob Taubes, Escatología occidental (Buenos Aires: Miño y Dávila editores, 2010), 90.

$54 D L, 143$.

55 Ibíd.
} 
modos, el Mesías o la esperanza mesiánica o el tiempo mesiánico ${ }^{56}$, es lo que puede constituirse en núcleo para la confluencia del judaísmo y el cristianismo. Apelando al Rabí Hillel -ubicado al fin del siglo II, por lo tanto no el Hillel Antiguo-, Lévinas dice que lo único que se conoce de ese maestro en el Talmud es la declaración: "Ya no hay Mesías para Israel". Porque el mesianismo sería una etapa superada. De ahí que sentencia: "El Mesías de los Judíos ya ha venido (ocho siglos antes de Cristo), en tanto que el de los otros pueblos es todavía futuro. Es preciso medir la enormidad de esta afirmación; su audacia es tal que la tradición rehúsa aceptarla"57.

Trasladado al plano de las relaciones cristianismo y el judaísmo, mientras para el primero el Mesías ya ha venido en Jesús de Nazaret, para el segundo todavía es futuro. Pero ambas tradiciones se unen en la espera, ya que los cristianos también esperan la Parusía del Señor. En suma, la esperanza mesiánica es el punto de convergencia de ambas religiones abrahámicas. A partir de esto, hay que intentar una síntesis que el propio Lévinas insinúa: "La noción de judeo-cristianismo que está en boca de todos evidentemente expresa un devenir y un ideal que debe concretarse en una síntesis inspirada por la era ecuménica; aunque dicha síntesis no logre superar todas las contradicciones" ${ }^{\prime \prime 8}$.

\section{Conclusión}

La crítica de Lévinas al cristianismo, que surge de la lectura de los ensayos reunidos en Difícil libertad, se centra especialmente en dos oposiciones: justicia vs. piedad "espiritual" y Torá vs. encarnación. De las dos críticas nos parece que la primera es más sólida en

El carácter irresuelto del Mesías como persona concreta o como "lo mesiánico" también se puede apreciar en los ensayos de Walter Benjamin. En el "Fragmento político-teológico" dice el pensador de la escuela de Frankfurt: "Sólo el Mesías mismo consuma todo suceder histórico, y en el sentido precisamente de crear, redimir, consumar su relación para con lo mesiánico." Walter Benjamin, Ensayos IV (Madrid: Biblioteca Nacional, 2002), 71. Para una interpretación del pensamiento de Benjamin, véase Michael Löwy, El judaísmo libertario en Europa Central. Un estudio de afinidad electiva (Buenos Aires: El cielo por asalto, 1997).

$D L, 373$. 
tanto se justifica ampliamente en el Antiguo Testamento, donde el mensaje de Dios, a través de los profetas, denuncia la tendencia de Israel de sustituir la justicia concreta hacia el prójimo por cultos y ceremoniales que Dios mismo detesta, mientras el pueblo no practica la justicia al huérfano, la viuda, los pobres y los extranjeros. Y, además, porque es cierto que algunas formas de piedad cristiana tienden también a sustituir la justicia por cultos y ceremoniales. El segundo eje de la crítica que se establece en el doble opuesto entre Torá vs. encarnación no parece muy sólida, pues Lévinas sustituye a esta última por la Torá, insistiendo en que Dios se hace más personal en ella que en la encarnación. Más allá de que la encarnación no es ni posible ni necesaria para el judío, nos parece que un Dios que se hace carne, se humaniza, se seculariza, es mucho más próximo a nosotros que Aquel que solo se revela en la Torá. El judío tiene todo derecho de rechazar la encarnación -como los griegos rechazan la resurrección de los muertos- pero en todo caso ese rechazo no puede explicarse reemplazando la encarnación por la ley divina y, sobre todo, subrayando la supremacía de esta última sobre la encarnación. Nada es más personal que un Dios que se hace carne y habita entre nosotros, por más escandalosa que dicha afirmación resulte.

El argumento más endeble de la exposición de Lévinas sobre la ley radica en negar el carácter de "yugo" en la vida del judaísmo. Por lo menos en el judaísmo del tiempo de Jesús de Nazaret y de la Iglesia primitiva, se ofrecen muchos testimonios de que la ley de Dios resultó un yugo imposible de sobrellevar por parte del pueblo. Es aquí donde es importante contrastar la visión de Lévinas con la reinterpretación que San Pablo hace de la Torá. El uso que el apóstol hace del término "Ley" es ciertamente diverso: el Antiguo Testamento, el Pentateuco, el decálogo, etc. Pero hay un concepto central: la Torá es la disposición y ordenamiento de Dios para la humanidad. En su intrincada elaboración teológica -sobre todo en las cartas a los Gálatas y a Romanos- Pablo introduce elementos acaso no considerados en al judaísmo rabínico como son: la fe, la gracia y el Pneuma. Si bien la justificación no es por la obediencia de la ley, ya que sus 
exigencias implican un cumplimiento absoluto que, al no lograrlo, colocan al ser humano bajo maldición, la fe y la gracia no anulan la ley. Mediante la introducción del nuevo factor, el Pneuma de Dios, Pablo afirma que el creyente puede cumplir con el ideal expresado en la Torá de Dios.

En lo que se refiere al papel del cristianismo en la historia universal, resulta importante observar que Lévinas, aunque lo rechaza, admite su lugar en esa historia. El rechazo que el judaísmo hace del cristianismo, según Lévinas, no debe atribuirse a una "terquedad absurda" sino al hecho de que muchas verdades del Antiguo Testamento que se relacionan directamente con la vida humana se pierden en la teología del Nuevo. La crítica tiene algo de justificación, pero quizás no sea exactamente la teología del Nuevo Testamento el lugar donde se hace ese reduccionismo, sino en las teologías posteriores que experimentan la influencia del pensamiento helénico y tienden a una espiritualización del mensaje.

De un modo más sutil, se puede observar en la crítica levinasiana al cristianismo en cuanto a su tendencia de este último a apropiarse de una tradición que, en su origen, no le pertenece. El cristianismo, en cualquiera de sus vertientes: católica, protestante y ortodoxa, debe tomar en serio este cuestionamiento. Sin embargo, la crítica de Lévinas es matizada al reconocer el aporte del cristianismo a la historia de Occidente y las muchas acciones de cristianos y cristianas que han expresado su amor, solidaridad y amistad hacia el pueblo judío.

Tal vez lo más esperanzador de la crítica de Lévinas al cristianismo radica en que todavía hay una posibilidad de convergencia. El núcleo de la misma es la esperanza mesiánica. Claro que, en su concepción del Mesías, Lévinas toma distancia de la visión cristiana de un Mesías personal y más bien la deriva hacia una perspectiva más amplia, en la cual el Mesías puede ser toda persona que sufre en lugar del otro. Pero más allá de las diferencias sustanciales entre ambas concepciones del Mesías, resulta altamente significativo que sea la "esperanza mesiánica" el punto posible de encuentro. Para 
el judaísmo, un Mesías que todavía espera y, para el cristianismo, también un Mesías que espera en su gloriosa Parusía. La esperanza mesiánica se torna, entonces, en un promisorio camino a recorrer por ambas religiones en un tiempo de la historia que nos impone el diálogo fluido y respetuoso entre judaísmo y cristianismo.

\section{Bibliografía}

Barth, Karl. Carta a los Romanos. Madrid: BAC, 1998.

Benjamin, Walter. Ensayos, IV. Madrid: Biblioteca Nacional, 2002.

Croatto, José Severino. "La dimensión política del Cristo libertador". En Míguez Bonino, José Cullmann, Oscar. Del evangelio a la formación de la teología cristiana. Salamanca: Sígueme, 1972.

Dussel, Enrique D. Antropología de la cristiandad. Buenos Aires: Guadalupe, 1974.

Dussel, Enrique D. y Guillot, Daniel E. Liberación latinoamericana y Emmanuel Lévinas. Buenos Aires: Bonum, 1975.

Küng, Hans. La encarnación de Dios. Introducción al pensamiento de Hegel como prolegómenos para una cristología futura. Barcelona: Herder, 1974.

Lévinas, Emmanuel. De otro modo que ser, o más allá de la esencia. Salamanca: Sígueme, 1995.

. Totalidad e infinito. Salamanca: Sígueme, 1977.

. Difícil libertad y otros ensayos sobre judaísmo. 2. Edición. Buenos Aires: Lilmod, 2008.

- Más allá del versículo. Lecturas y discursos talmúdicos. Buenos Aires: Ediciones Lilmod, 2006.

Löwy, Michael. El judaísmo libertario en Europa Central. Un estudio de afinidad electiva. Buenos Aires: El cielo por asalto, 1997. 
Míguez Bonino, José. “El Reino de Dios y la historia". En Padilla, C. René (editor). El Reino de Dios y América Latina. El Paso: CBP, 1975.

Roldán, Alberto F. "El carácter ambivalente de los conceptos carne y carnalidad en la teología cristiana". Enfoques 1, año XXI (2010): 53-69.

. "La kénosis de Dios en la interpretación de Gianni Vattimo. Hermenéutica después de la cristiandad". Cuadernos de Teología, volumen XXIII (2004): 329-342. . Reino, política y misión. Lima: Ediciones Puma, 2011.

Roldán, David A. “Emmanuel Lévinas y la Onto-teo-logía: Dios, el prójimo y yo". Cuadernos de Teología, vol. XXI (2002): 229-243.

Santa Biblia. Nueva Versión Internacional. NVI, Miami: Sociedad Bíblica Internacional, 1999.

Santa Biblia. Reina Valera 1960. Miami: Editorial Vida, 1978.

Schlier, Heinrich. La carta a los Gálatas. Salamanca: Sígueme, 1975.

Segundo, Juan Luis. El dogma que libera. Santander: Sal Terrae, 1989.

Sudar, Pablo. El rostro del pobre. Inversión del ser y revelación más allá del ser en la filosofía de Lévinas. Su resonancia en la filosofía y teología de la liberación en Latinoamérica. Buenos Aires: UCA/Editora Patria Grande, 1981.

Suscasas, Alberto. Lévinas: Lectura de un palimpsesto. Buenos Aires: Ediciones Lilmod, 2006.

Taubes, Jacob. Escatología occidental. Buenos Aires: Miño y Dávila editores, 2010. . La teología política de Pablo. Madrid: Trotta: 2007.

Wolff, Walter. Antropología del Antiguo Testamento. Salamanca: Sígueme, 1975.

Recibido: 20 de mayo de 2011 Aceptado: 29 de septiembre de 2011 